Review

\title{
Clinical Importance of the Posterior Inferior Cerebellar Artery: A Review of the Literature
}

\author{
Hui-Lei Miao ${ }^{1,3^{*}}$, Deng-Yan Zhang ${ }^{1,2^{*}}$, Tao Wang ${ }^{1^{*}}$, Xiao-Tian Jiao ${ }^{1}$, Li-Qun Jiao ${ }^{1^{\bowtie}}$ \\ 1. Department of Neurosurgery, Xuanwu Hospital, Capital Medical University, No. 45, Changchun Street, Beijing 100032, China. \\ 2. School of General Practice and Continuing Education, Capital Medical University, Beijing 100069, China \\ 3. Peking Union Medical College and Chinese Academy of Medical Sciences, Beijing 100730, China. \\ * These authors contributed equally. \\ $\square$ Corresponding author: Prof. Li-Qun Jiao, Department of Neurosurgery, Xuanwu Hospital, Capital Medical University, No. 45, Changchun Street, Beijing, \\ China. Tel: +861083198836. E-mail: liqunjiao@sina.cn. \\ (0) The author(s). This is an open access article distributed under the terms of the Creative Commons Attribution License (https://creativecommons.org/licenses/by/4.0/). \\ See http://ivyspring.com/terms for full terms and conditions.
}

Received: 2020.06.05; Accepted: 2020.10.07; Published: 2020.10.18

\begin{abstract}
The posterior inferior cerebellar artery (PICA), with its unique anatomical complexity, is of great clinical importance and involved in many diseases including aneurysm, ischemic stroke, neurovascular compression syndrome (NVCS), arteriovenous malformation (AVM), and brain tumor. However, a comprehensive systematic review of the importance of the PICA is currently lacking. In this study, we perform a literature review of PICA by searching all the associated papers in the PUBMED database hoping to provide a better understanding of the artery. The PICA has tortuous and variable course and territory, divided into 5 segments. Various aneurysms involving PICA were not uncommon, of which the treatment is challenging. The PICA infarct typically manifests lateral medullary syndrome (LMS) and is more likely to cause mass effects. The PICA frequently compresses the medulla and the cranial nerves resulting in various neurovascular compression syndromes (NVCS). Arteriovenous malformation (AVM) fed by PICA are associated with aneurysm and dissection which have high risk of rupture and worse outcome. PICA injured by head trauma can cause fatal SAH. VA terminating in PICA probably cause Bow hunter's syndrome (BHS). The PICA supplies many brain tumors and can be used in intracerebellar chemotherapy. The PICA can be exposed and injured during surgeries especially in telovelar approach, and it also plays an important role in bypass surgeries, hinting the surgical importance of PICA. In conclusion, PICA is very important in clinical practice.
\end{abstract}

Key words: posterior inferior cerebellar artery, clinical importance, anatomy, aneurysms

\section{Introduction}

The posterior inferior cerebellar artery (PICA) usually originates from the vertebral artery (VA) at an average distance of approximately 16 or $17 \mathrm{~mm}$ below the vertebrobasilar junction [1,2]. The VA, arising from the subclavian artery, is classically divided into 4 segments. The first three segments were extracranial and the fourth segment is entirely intracranial and terminates with forming the basilar artery (BA). It is the fourth segment of VA that gives off the PICA, which is the largest branch of VA [3-5]. The trunk of PICA is divided into five segments (Figure 1): (1) the anterior medullary segment, which begins at the origin of the PICA and ends at the level of a rostrocaudal line that passing through the most prominent part of the inferior olive; (2) the lateral medullary segment, which extends from the level of the most prominent point of the olive to the level of the origin of the glossopharyngeal (CN IX), vagus $(\mathrm{CN} \mathrm{X})$, and accessory (CN XI) rootlets; (3) the tonsillomedullary segment, which begins where the PICA passes posterior to the CN IX-XI and ends at the midpoint of the PICA's ascent toward the roof of the fourth ventricle along the medial surface of the tonsil; (4) the telovelotonsillar segment, which begins where the PICA ascends to the mid-level of the medial surface of the tonsil and ends where the artery exits the fissures between the tonsil, vermis, and hemisphere to reach the suboccipital surface; (5) the 
cortical segment, this segment begins where the PICA leaves the groove between the vermis, tonsil and hemisphere, and includes the terminal cortical branches $[1,6]$. The trunk of PICA gives rise to perforating, choroidal, and cortical branches [1]. The PICA supplies the medulla, the choroid plexus and tela choroidea of the fourth ventricle, the tonsils, the inferior vermis, and the inferior aspects of the cerebellar hemispheres [1, 7]. Furthermore, PICA mostly supplied the choroid plexus on the roof and the median opening of the fourth ventricle and gave the majority of branches of choroid plexus [8].

The PICA shows a high frequency of variations. The PICA is observed to be hypoplastic in 15 - 32\% of the cases $[9,10]$. Unilateral absence of PICA is reported in $6-26 \%$ of cases, absence bilaterally of PICA is reported in $2-3.6 \%$ of cases [1, 11-14]. If one PICA is hypoplastic or absent, the ipsilateral anterior inferior cerebellar artery (AICA) or the contralateral PICA is larger and supplies the area normally nourished by the ipsilateral PICA [10]. Duplication of the PICA occurs in $2-6 \%$ of hemispheres [1, 10, 15]. Double origin of the PICA is a rare variation different from duplication, in those cases two distinct PICAs with separate origins converge distally. The reported prevalence of this variation is about $1.45 \%$ [16]. This type of variation is closely related to aneurysm formation, and the incidence of aneurysms in double-origin PICA ranges from 50 - 71\% [17]. Fenestration is a rare but well-known arterial anatomic variation in which a segment of artery divides into two distinct lumens that reunite distally. The incidence of PICA fenestration is reported to be $0.3 \%$ [18]. Some investigators hold the view that variations such as duplications and fenestrations were prone to the coexistence of vascular anomalies including aneurysms, vascular malformations, dissections due to the abnormal vascular structure and hemodynamics [5].The VA terminating in the PICA is reported in $2.8-7 \%$ patients, which is also one of the most common variations of VA [3, 18-20]. This variation may have a detrimental impact on cerebral hemodynamics [21]. The location of the origin of the PICA is extremely variable. The PICA origins at all points along the intradural VA are reported [1, 2]. An extradural origin PICA from the VA is not rare. The frequency of an extradural origin of the PICA ranges from $0.4 \%$ to $20.8 \%[1,4,12,18,19,22-25]$. The extradurally located PICAs are exposed to injury during posterior approaches to the lower brainstem and upper cervical spine. The PICA may also arise from the BA. Overall, a PICA arising from the BA appears in $6-11 \%$ of cases [12, 20]. But Icardo et al [9] reported that the PICA originated from the BA in $53.33 \%$ cases, of which $25.0 \%$ were directly from the lower third of the BA and $28.33 \%$ had a common trunk with the AICA. The AICA-PICA common trunk anomaly is one of the most common variants in the posterior circulation, and it has a prevalence of 20 $24 \%$ based on retrospective studies [26]. Recognizing this anomaly is important because inadvertent injury to this variant at its origin during surgery would



Figure 1. Normal segmental anatomy of the PICA. 
result in strokes involving both PICA and AICA territories. PICAs origins from other arteries such as internal carotid artery, primitive hypoglossal artery, primitive trigeminal artery and posterior meningeal artery have also been reported [27-30]. Rarely, the variation of primitive trigeminal artery (PTA), which is the most common persistent carotid-basilar anastomose, could originate from internal carotid and continue as PICA [31]. The anatomic variants of PICA are shown in Figure 2A-F.

Therefore, the PICA is of great clinical importance with its unique anatomical complexity and is involved in many diseases, including ischemic stroke, aneurysm, neurovascular compression syndrome (NVCS), arteriovenous malformation
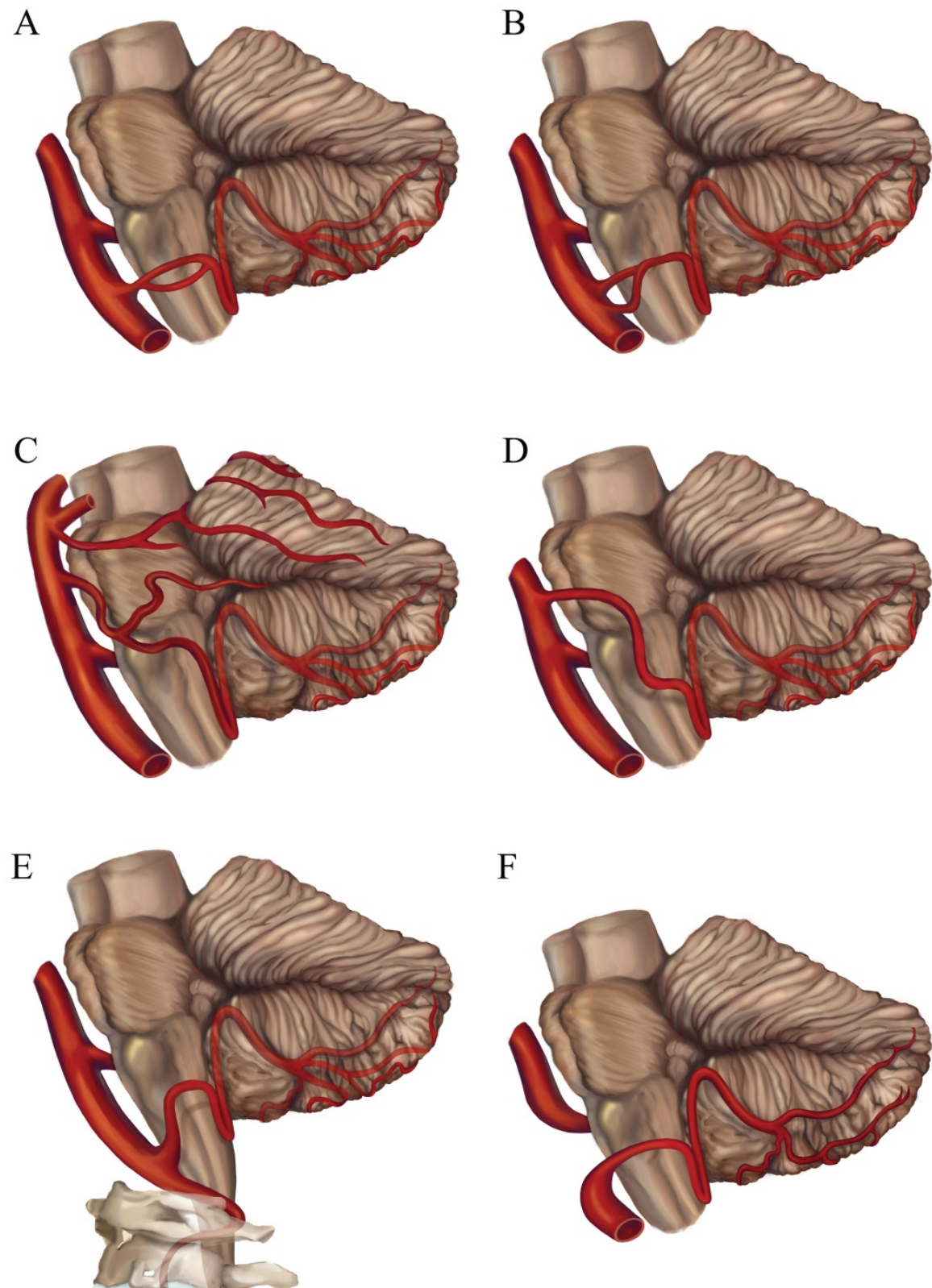

$\mathrm{F}$

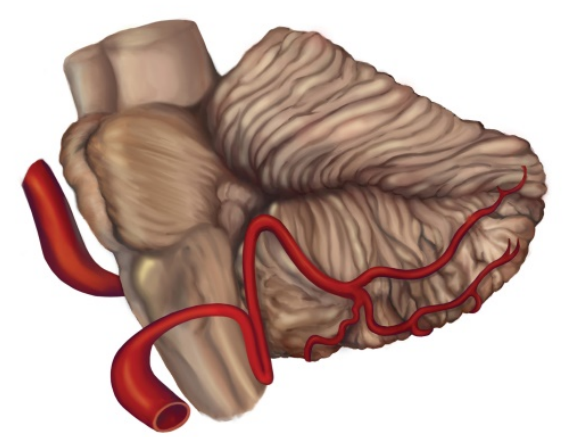

Figure 2. The anatomic variants of the PICA. (A) Fenestration of the PICA; (B) Double origin of the PICA; (C) The AICA-PICA variant; (D) The PICA originates from the BA; (E) The extradural origin PICA; (F) The VA terminates in the PICA. VA, vertebral artery; BA, basilar artery; AICA, anterior inferior cerebellar artery; IX, glossopharyngeal nerve; $\mathrm{X}$, vagus nerve; $\mathrm{XI}$, accessory nerve; $\mathrm{XII}$, hypoglossal nerve. 


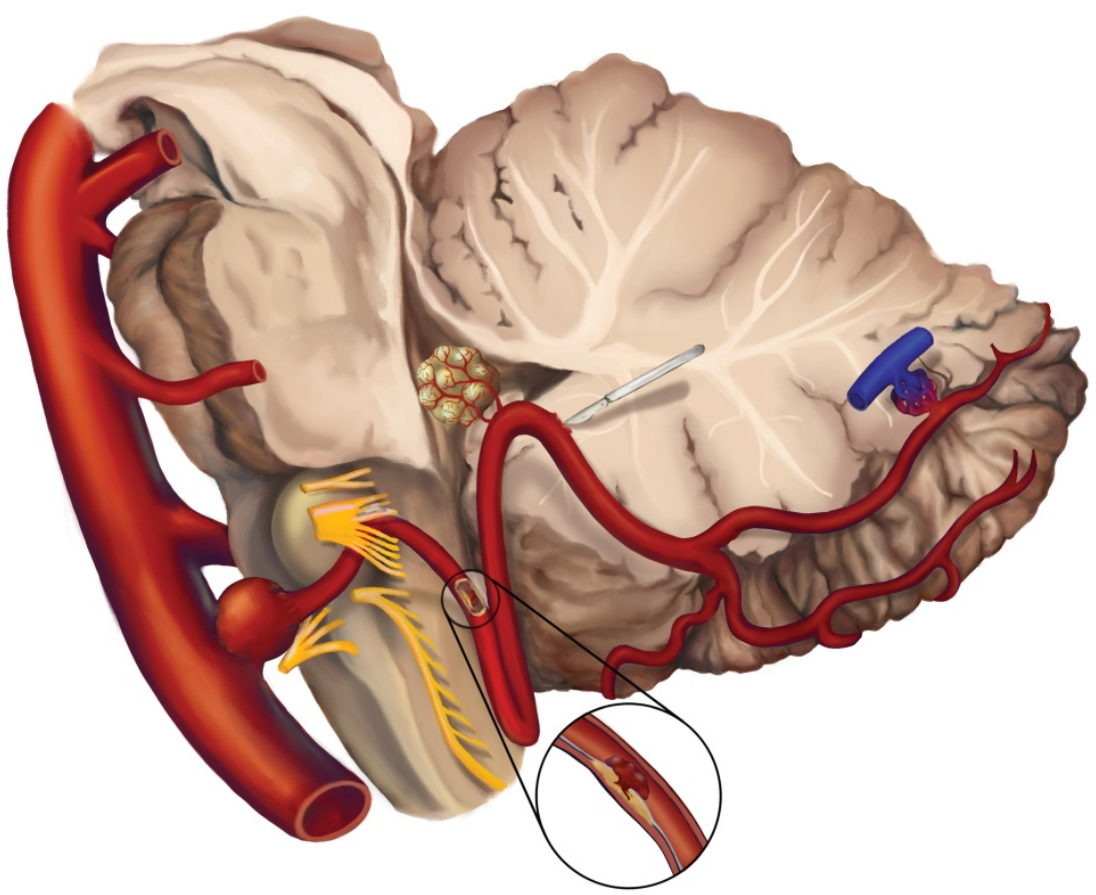

Figure 3. The overview of the diseases involving PICA. Common diseases including aneurysm, ischemic stroke, neurovascular compression syndrome (NVCS), brain tumors supplied by PICA, surgical injury, arteriovenous malformation (AVM) on PICA are illustrated.

\section{Aneurysm}

The most common disease involving PICA is aneurysm. About $1.4-4.5 \%$ of all intracranial aneurysms originate from PICA [32-34]. PICA aneurysms are heterogeneous in both location and morphology, which could arise in any of the 5 segments of PICA while the VA-PICA junction is most frequently involved. Distal PICA aneurysms only account for less than 30\% [35, 36]. Morphologically, PICA aneurysms display saccular, dissecting, and fusiform pattern. Richard et al reported that most of the ruptured PICA aneurysms were saccular whereas the PICA was more inclined to form non-saccular aneurysms than other arteries [37]. Although the dissecting aneurysms account for less than $1 / 3$ of all the PICA aneurysms, the specificity in clinical features and treatment options and worse course call for special attentions [37-40]. Unusual aneurysms located in AICA-PICA variant, the bifurcation of persistent primitive hypoglossal artery (PPHA)- PICA, the fenestration of the PICA, the double origin of the PICA and extracranial PICA were also reported [41-45]. Giant aneurysms and multiple peripheral aneurysms were also found in previous studies [46-48].

PICA aneurysms have a broad spectrum of clinical and radiological manifestations. Most patients present symptoms associated with subarachnoid hemorrhage (SAH). The headache is more common in occipital area and neck, compared with supratentorial aneurysms [49-51]. More than $83 \%$ of the patients with a ruptured aneurysm developed intraventricular hemorrhage (IVH) and obstructive hydrocephalus as PICA was adjacent to the fourth ventricle anatomically [52]. Localizing symptoms appeared when cranial nerves and structures of brain stem and cerebellum were involved due to compression or infarcts [53-55]. Proximal PICA dissecting aneurysms tended to cause infarcts compared with other PICA aneurysms [40, 56, 57]. The clinical features of brain infarcts will be described in the following part. Although abducens nerve was not directly adjacent to PICA, ruptured PICA aneurysm could result in isolated abducens nerve palsy, which was possibly associated with the hemodynamics of aneurysmal rupture instead of direct compression [58]. Burkhardt et al demonstrated ruptured PICA aneurysm was an independent risk factor of abducens nerve palsy [59]. Giant aneurysms might be misdiagnosed as tumors of posterior fossa due to similar symptoms and imaging features which were sometimes indistinguishable even with magnetic resonance angiography (MRA) and digital subtraction angiography (DSA) [46, 47]. Computed tomography angiography (CTA) is insensitive to the distal PICA aneurysms resulting from the thin lumen of PICA. Yuan's retrospective study included 18 confirmed cases with distal PICA aneurysm; only 2 of them were identified by CTA [60].

PICA aneurysms have a high tendency to rupture even small in size due to its relatively fragile vessel wall [61]. The average size of ruptured PICA 
aneurysm was about $6 \mathrm{~mm}$, with a minimum of $1 \mathrm{~mm}$ $[34,36,37]$. The rupture rate of PICA aneurysms ranged from $77 \%$ to $88 \%$ in some large retrospective studies [33, 34, 36, 62]. More than $20 \%$ of the ruptured intracranial aneurysms were from PICA aneurysms though with low incidence [32, 37]. The mortality resulting from recurrent hemorrhage within 48 hours of ruptured PICA aneurysms was 3 times higher than anterior circulation aneurysms [63, 64]. As a consequence, the early identification and treatment are of vital importance. For unruptured intracranial aneurysms, patients with documented enlargement during follow up, a history of SAH or a family history of intracranial aneurysms are recommended treatment. However, there is still no consensus regarding the treatment indications for PICA aneurysm due to its rarity and diversity of location and morphology.

Endovascular treatment (EVT) has been the dominant treatment strategy of PICA aneurysms recently, which was applied in $55.4 \%$ of the ruptured PICA aneurysms [32]. EVT reduces the risk of direct brainstem injury and anesthesia related complications, which is more preferable for patients with poor clinical status [34]. EVT strategies such as stand-alone coiling, stent-assisted coiling, microcatheter-assisted coiling, flow diversion, parent artery occlusion with coils were successfully used to treat PICA aneurysms [33, 65-73]. The treatments of PICA dissecting aneurysms were prone to require vessels sacrifice [38]. Nevertheless, EVT related complications including intraprocedural ruptures and new-onset infarcts are not rare [33]. Chen's study even reported that the morbidity of EVT related imaging infarcts was up to $33 \%$, most of them didn't show apparent symptoms fortunately [65]. A meta-analysis suggested PICA aneurysms treated with EVT had a higher recurrence rate and lower occlusion rate than those treated with surgery [35]. Robert et al also reported $29.4 \%$ of the patients who underwent EVT required retreatment due to aneurysm recurrence [72]. The safety and efficacy of EVT still need to be improved.

Broadness of the neck, non-saccular morphology, small caliber of the PICA, small angulation between the PICA and VA, the presence of vasospasm in ruptured cases, and tortuosity of the PICA sometimes make endovascular approaches very difficult. In cases of massive IVH or hydrocephalus, EVT would never be able to offer decompressive effect. Hence, in the actual endovascular era, surgical treatment remains a valid option for $28 \%$ of PICA aneurysms while $4.8 \%$ of non-PICA aneurysms [32]. Microsurgical treatments including clipping, trapping, resection, and a variety of bypasses procedures have been used to treat PICA aneurysms and acceptable clinical outcomes have been obtained $[61,74-80]$. However, the deep location of the PICA aneurysms, the intimate relationship of PICA aneurysms with the lower cranial nerves, as well as the presence of subarachnoid hemorrhage around the brainstem make microsurgical dissection of these aneurysms difficult. Previous reports noted that new cranial nerve palsies occurred at an incidence of 20 $60 \%$ after surgical treatment [81]. For many years, controversy has raged over the pros and cons of the various surgical routes to approach PICA aneurysms. The far-lateral approach is a standard approach for PICA aneurysms clipping [75, 77, 78, 82, 83].

Compared to saccular aneurysms, dissecting aneurysms in PICA had worse clinical outcomes including longer hospital stays, more likely to receive extraventricular drain and ventriculoperitoneal shunt, as well as more ischemic infarcts when treated with EVT. Therefore, bypass surgery was recommended to patients with dissecting PICA aneurysms $[38,84,85]$.

\section{Ischemic stroke}

PICA plays an important role in the blood supply of cerebellum, and the PICA territory is the most common area of cerebellar ischemic stroke of, accounting for $40 \%$ [86]. The cerebellar branches and choroidal branches of PICA have abundant anastomoses with superior cerebellar artery (SCA) and AICA while medullary branches are lack of anastomoses. Thus, the most frequently involved ischemic region of the PICA infarct is the dorsal lateral medulla supplied by the medullary branches. This causes lateral medullary syndrome (LMS), which will be detailly described later. Except LMS, the infarcts of the medial branch of the PICA (mPICA) could lead to vertigo, nausea, vomiting and postural instability because of inadequate blood flow of vestibulocerebellum. Isolated vertigo could occur in isolation $[87,88]$. The infarcts of the lateral branch of the PICA (IPICA) could cause dysmetria and hypotonia of ipsilateral limb [89]. Rarely, the PICA infarcts might present acute hearing loss when PICA or basal artery gave rise to the internal auditory artery $[90,91]$.

Various pathogenesis of PICA infarcts includes large artery atherosclerosis, cardiogenic embolism, in situ branch artery disease of PICA and VA dissection [92]. Lee et al reported that greater angle between PICA and VA was more likely to result in cardioembolic occlusion of PICA [93]. Although patients with PICA dissection tended to hemorrhage compared with ischemia [94], Junpei et al still found that isolated PICA dissection caused $6 \%$ of the PICA region infarcts by reviewing 167 cases, equal to VA 
dissection, which hinted the undervalued clinical importance of PICA dissection [95]. Jeong et al reported a rare case of PICA infarct after cervical chiropractic manipulation [96]. Extradural origin of PICA could be injured accidently by the cervical surgery [97]. As a result, the history of mechanical injury and surgery should be noticed when faced with PICA infarct of unknown origin.

As known computer tomography (CT) can rarely identifies early-stage infarcts and the sensitivity of diagnosing infarcts in posterior fossa is even lower due to the artifacts of skull base [98]. Magnetic resonance imaging (MRI) is preferable in the early diagnosis of infarcts and T2-weighted images (T2WI) are more sensitive than fluid-attenuated inversion recovery (FLAIR) in the identification of posterior fossa infarcts [99, 100]. Diffusion-weighted magnetic resonance imaging (DWI) is widely used in early infarcts identification. However, vertebrobasilar strokes were prone to show false-negative pattern in DWI probably because of the tiny lesions and magnetic susceptibility artifacts [101]. What's more, a three-component bedside oculomotor examination called HINTS is superior to MRI in the detection of mPICA infarcts. HINTS included horizontal head impulse test, nystagmus and test of skew, which indicated the importance of specific physical examinations $[102,103]$.

Treatment strategies vary from the etiology of infarcts. Similar to other ischemia strokes, intravenous recombinant tissue-type plasminogen activator (rt-PA) is recommended in thromboembolic PICA infarcts [104]. Selective intra-arterial rt-PA has been used in acute PICA infarcts recently [105]. For those infarcts caused by dissection, the efficiency and risk of hemorrhage of rt-PA were still uncertain [94]. All patients require secondary stroke prevention in chronic stage [95, 106]. Catastrophic complications such as increased intracranial pressure and obstructive hydrocephalus should be monitored. As PICA locates in the cramped posterior fossa, the infarct tissues of PICA region and surrounding edema take up larger space within posterior fossa, leading to medulla compression and hydrocephalus. According to Koh's study involving 90 patients with isolated cerebellum infract, $60 \%$ of the patients who suffered mass effect had PICA territory infarcts [107]. Drainage of cerebrospinal fluid and decompressive craniectomy could be applied if need. However, the outcome of space-occupying cerebellar infarction after different treatment strategies was still unclear [108-110].

\section{Lateral medullary syndrome}

LMS, also named Wallenberg syndrome or posterior inferior cerebellar artery syndrome, is due to damage to the lateral part of medullary oblongata caused by vascular events. The most frequently involved vessels are the PICA or the VA [111, 112]. LMS is the most prevalent posterior circulation ischemic stroke syndrome and is the typical presentation of PICA territory infarcts. More than 20\% of ischemic strokes appeared in posterior circulation and half of them manifested LMS as estimated [112, 113]. Anatomically PICA is the relevant supplying artery of LMS. However, previous studies demonstrated that the VA which gave off PICA was the most responsible artery, accounting for $67 \%$, followed by PICA (10\%). Although atherosclerosis was still the most common cause of vascular events leading to LMS, PICA occlusion causing LMS was thought to be more relevant to cardiogenic embolism compared with other vessels [111, 114]. Rarely, a fraction of isolated PICA dissection cases could present LMS [111]. PICA dissecting aneurysms resulting in LMS was also reported [57]. Razak et al. also considered extradural origin of PICA as a risk factor of LMS [116].

The clinical manifestations of LMS are various depending on the exact location of the damage. Vertigo with nystagmus, nausea and vomiting appear due to vestibular nucleus and vestibular-cerebellar connections involvement. Dysphagia, dysphonia and dysarthria, sometimes combined with ipsilateral loss of gag reflex and hiccup ascribe to defect of nucleus ambiguus, glossopharyngeal and vagus nerve, which is more significant in LMS patients associated with the evaluation and follow-up care. Ipsilateral ataxia is correlated with cerebellar peduncles, spinocerebellar fibers and inferior cerebellar hemisphere. Ipsilateral Horner syndrome shows decreased pupil size, a drooping eyelid and decreased sweating on the ipsilateral face due to sympathetic fibers defects. Impairment of pain and thermal sensation on the ipsilateral face and on the contralateral trunk and limbs are associated with impaired nucleus spinalis nervi trigemini or its spinal tracts, and spinothalamic tracts respectively. Different combination of these symptoms above can be found in LMS patients while more than $90 \%$ of the patients have sensory symptoms, which are the most frequent manifestations. These symptoms can appear either acutely or gradually, progressing over several hours to several days. The ratio of sudden and chronic course is about $3[111,114,117]$.

The diagnosis and treatment is similar to any ischemic stroke. In particular, dysphagia management and speech therapy assessment should be included for patients with corresponding symptoms. Overall LMS patients have a better prognosis than most other stroke syndromes, even those with severe dysphagia 
$[114,117]$.

\section{Neurovascular Compression Syndrome}

NVCS covers a wide range of diseases caused by vessels compressing a variety of neural structures, and it is clinically characterized by functional disturbances of these effected structures [118, 119]. The PICA frequently forms complex loops on the side of the brainstem, which distorts the medulla and the cranial nerves and results in various NVCSs.

\section{Glossopharyngeal Neuralgia (GPN)}

GPN is characterized by a sudden onset of lancinating pain in the posterior pharynx, base of tongue, tonsillar region, or deep ear, that is, the sensory distribution of the auricular and pharyngeal branches of the CN IX, with an incidence of $0.7 / 100$ 000 per year $[120,121]$. The PICA is the primary culprit artery of GPN due to its close relationship with CN IX. Xia et al reported in nearly $90 \%$ of the patients, the CN IX was compressed by PICA, solely $(72.3 \%)$ or combined with other vessels $(17.2 \%)$ in their cohort involving 228 GPN patients [116]. Furthermore, the neurovascular conflict involving PICA and both $\mathrm{CN}$ IX and $\mathrm{CN} \mathrm{X}$ was also reported, which was referred to as vago-glossopharyngeal neuralgia [122]. Patients with vago-glossopharyngeal neuralgia manifested with not only GPN syndrome but also symptoms associated with excessive parasympathetic vagal outflow such as bradycardia and asystole [123, 124].

\section{Hemi-Laryngopharyngeal Spasm (HeLPS)}

HeLPS is a newly defined rare syndrome associated with the compression of the CN X. Patients with HeLPS presented episodic throat contractions and grievous feeling of chocking that increased in severity, frequency, and duration over years. The syndrome was easily misdiagnosed as psychiatric illness or laryngeal diseases. Cases with HeLPS have been reported in at least 4 languages since 1926, which hinted the possibly underestimated incidence [125-127].

\section{Hemifacial Spasm (HFS)}

HFS is the most common neurovascular syndrome characterized by paroxysmal, involuntary twitching of facial muscles in the region innervated by ipsilateral facial nerve (CN VII), with a prevalence of $7.4 / 100000$ in men and 14.5/100000 in women [128, 129]. Although AICA has the closest relation with $\mathrm{CN}$ VII anatomically, actually the tortuous PICA is the most frequent offending vessel in HFS, accounting for $47.2 \%$, followed by AICA [130, 131]. Chung et al noted that PICA compression was prone to left-sided symptoms [132].

\section{Trigeminal neuralgia (TN)}

$\mathrm{TN}$ is an paroxysmal, lancinating and annoying facial pain syndrome occurring in the region innervated by the trigeminal nerve $(\mathrm{CN} \mathrm{V})$. The most common offending vessels are the SCA, AICA and vertebrobasilar trunk $[133,134]$. Very rarely, TN could result from the PICA associated with the PTA as mentioned before [31]. Several cases demonstrated that the artery that originated from the PTA and terminated as the sole PICA caused TN [134,135].

\section{Medullary Compression Syndrome (MCS)}

MCS is the syndrome associated with the compression of medulla, mainly manifesting as hypertension. The PICA was reported as the dominant offending vessel [136-138]. As known, the ventrolateral medulla plays an important role in the regulation of tonic cardiovascular reflexes [139-141]. Therefore, the compression of the ventrolateral medulla by the PICA was considered as an important cause of essential hypertension [136, 138]. Besides hypertension, dysesthesia, dysarthria, and hemiplegia could occur in MCS patients [142]. Simpson et al reported a rare case that presented hemibody pain, MRI demonstrated indentation and displacement of the lower part of contralateral medulla by a loop of PICA [143].

Other NVCSs such as geniculate neuralgia, trigeminal neuralgia and vestibular paroxysm could result from compression of the corresponding cranial nerve by PICA in a few cases [144-146]. Multiple cranial neuropathy caused by the offending PICA were also described, in these cases, patients presented with simultaneous trigeminal neuralgia and HFS or concurrent HFS and GPN or trigeminal neuralgia and GPN $[147,148]$.

The pathophysiology mechanisms of these NVCSs are similar, which includes demyelination induced by pressure and ectopic generation and ephaptic transmission of the impulses along the compressed nerve $[121,149]$. The diagnosis of these diseases mainly depends on specific clinical manifestations and MRI evidence. Microvascular decompression (MVD) is a well-established treatment for NVCS [150]. High effective rates and good clinical outcomes have been reported with MVD in patients with these diseases above [120, 126, 148, 151].

\section{Arteriovenous malformation}

AVM caused by congenital dysplasia of mesoderm vessels is a group of vasculatures that consist of feeding arteries, abnormal vascular nest and draining veins, with a detecting rate ranging from 1.10 to 1.4 per 10000 person-years [152]. 5-9\% of them are posterior fossa AVMs [1]. PICA could serve as the 
feeding artery of posterior fossa AVMs [153-156]. The most common clinical manifestation of posterior fossa AVMs was hemorrhage; some patients also presented seizure, headache, and dysphoria et al [153]. Strikingly, feeding arteries aneurysms associated with AMVs drew attention due to the increasing risk of rupture and hemorrhage. It was supposed that the formation of aneurysms was probably associated with the high flow, which resulted from AVMs or the congenital impaired vessel walls [154, 157, 158]. The PICA is more prone to form aneurysms associated with AVMs because its tortuous anatomic course more likely leads to hemodynamic abnormity [159]. Kaptain et al presented $81 \%$ of the PICA aneurysms associated with AVMs located in the distal segments of PICA [154], David's study showed distal PICA aneurysms were frequently related to small AVMs [160]. Furthermore, as proved, the risk of aneurysms rupture of PICA was significantly higher than AVMs rupture in PICA-AVM-aneurysm complex [157]. Besides aneurysms, dissection of the PICA distal segment causing subarachnoid hemorrhage (SAH) associated with AVM was also reported. The possible pathogenesis was the high flow rates and shearing force in the highly tortuous segment [155].

Hemorrhagic stroke caused by posterior fossa AVMs and their associated diseases had worse outcome compared with supratentorial AVM, which hinted the importance of early diagnosis and treatment [153]. DSA is the golden standard of diagnosis. Once diagnosed, the treatment strategies consist of microsurgical resection, endovascular embolization, stereotactic radiotherapy and the combination of these options. Observation is also a choice for those patients with mild symptoms [153]. What's more, the treatment of PICA aneurysms and dissection associated with AVMs were still controversial. Some studies demonstrated AVM should be treated primarily because the associated diseases would cure after the removal of AVM [154, $155,161]$. Other studies proposed the treatment of aneurysms should be prior due to the higher risk of rupture [154, 157, 162]. In some cases, the PICA aneurysm and AVM could be treated simultaneously, with surgery or endovascular embolization $[158,162]$.

\section{Other diseases}

\section{Traumatic PICA injury}

Trauma to the head may cause various injuries including blood vessels injuries. PICA can be injured manifesting traumatic aneurysms, traumatic arteriovenous fistula, and direct rupture [163-170]. Head trauma can result in acceleration and deceleration of the cerebellum, forming shearing forces leading to vessels torsion, overstretching and tearing, which is the possible mechanism of the injury of PICA [163, 166, 167, 169].

Traumatic aneurysms account for less than $1 \%$ of intracranial aneurysms and $10 \%$ of them involve posterior circulation, which is the most frequent PICA injury. The formation of traumatic aneurysms is related to blunt or penetrating injury and mostly associated with skull fractures. Children and males are prone to suffer from traumatic aneurysms because of higher trauma incidence [163, 167, 171]. Traumatic aneurysms can be clarified as true aneurysms, false aneurysms, and dissecting aneurysms. The most common type is false aneurysm [172]. The aneurysms mostly locate in the origin of PICA and proximal PICA [164-166]. About 50\% of the traumatic aneurysms rupture and cause catastrophic outcomes. The mortality rates range from $32 \%$ to $54 \%$. Most of the ruptures are delayed onset and the average time from injury to rupture was 14-21 days, rarely several hours or several years. Delayed SAH is the most common clinical manifestation of PICA traumatic aneurysms rupture. DSA is still the golden standard for detection [163-166]. However, the differential diagnosis of the rupture of traumatic aneurysms and pre-existing aneurysms is hard. Pre-existing aneurysms should be strictly excluded by the comparation of DSA results before and after trauma, which is extremely difficult. During clinical practice, the history of head trauma, young and male patients, the location of the aneurysms near falx edge and far away from branching points all support the diagnosis of traumatic aneurysms [163, 166]. When the diagnosis is confirmed, the early intervention to PICA aneurysms is recommended.

Besides aneurysms, traumatic arteriovenous fistula of PICA was rarely reported after penetrating injury, which was cured by endovascular embolization [168]. Cases with direct rupture of PICA causing death were also reported. The confirmation relied on autopsy after excluding aneurysms, atherosclerosis and medionecrosis $[169,170]$.

\section{Bow hunter's syndrome}

Bow hunter's syndrome (BHS), officially named rotational VA occlusion, is a rare disease caused by mechanical and reversible occlusion or compression of the VA and lack of blood supply when rotate or stretch the neck [173-175]. BHS often occurs in males in their sixties. The blood supply of the posterior circulation is commonly defective, the most common reason is VA hypoplasia and the VA terminating in PICA followed [173, 174]. The clinical manifestations vary from mild vertigo to medulla stroke. Jost's study summarizing 126 cases showed syncope, drop attacks, 
vertigo, dizziness and impaired vision were more common symptoms, while hemiparesis, numbness, near loss of consciousness and headache and so on were less common [173]. The final diagnosis depends on DSA which can reveal the stenotic or compressed arteries when rotate the neck. Recently, transcranial doppler (TCD) sonography has been used in the evaluation of the disease [174]. Due to the limited number of patients, there is no agreement on standard treatment. Most of the patients underwent decompression and/or fusion surgery. A few patients chose conservative therapy including aspirin and cervical collar which could restrict the rotations of neck. Several cases were treated with endovascular intervention [173, 174]. Rarely, one patient without obvious compression site received PICA-to-PICA in situ bypass surgery to rebuild the blood supply [176].

\section{Brain tumors}

The PICA can supply many brain tumors including hemangioblastoma, ependymoma, subependymoma, papillomas of the choroid plexus and meningioma [8, 177-180]. Patel et al reported a patient whose retromedullary hemangioblastoma was misdiagnosed as PICA aneurysm and angiography showed supply from PICA. Endovascular embolization failed and microsurgical specimen revealed the diagnosis of hemangioblastoma, which hinted the rare differential diagnosis of PICA aneurysms [177]. Yan et al reported that a meningioma at craniocervical junction was adhering to VA and PICA. Meningioma in this area was mostly supplied by meningeal branches of VA, rarely by PICA. The preservation of VA and PICA was very important in the dissection surgery [178]. The fourth ventricle tumors supplied by PICA and its branches deserved attention, which could be adjacent to and even encase the PICA. The approach to the fourth ventricle tumors and the microsurgical dissection should be extremely meticulous to avoid PICA injury $[179,180]$. The association between tumors and vessels should be evaluated by image examination such as DSA, CTA and MRA before operation if need. Besides surgery, PICA recently was used to treat lung adenocarcinoma with solitary cerebellar metastasis through microcatheter interventional therapy combined with bronchial artery, which showed safety and short-term efficacy. This new strategy benefited from the small space of posterior fossa and the direct saturation of the drug of cerebella tumor using PICA, which increased the local drug concentration [181]. In conclusion, PICA is essential for the diagnosis and treatment of some brain tumors and should be protect carefully.

\section{Surgical exposure and application of PICA}

Due to a great number of adjacent structures and complexity of the anatomy, even multiple variations existing, the PICA is quite possibly injured in surgeries. The spectrum of the consequence varies from spasms of branches to catastrophic occlusion and hemorrhage [182]. The damaged locations probably make a difference depending on the number of anastomotic branches. The most mentioned surgical approach that may injure PICA is the telovelar approach through cerebellomedullary fissure corridors to the fourth ventricle, which can be utilized in fourth ventricular tumors resection, as well as arteriovenous malformation and aneurysms of PICA [183-185].

The telovelar approach is carried out by suboccipital craniotomy, cerebellar hemispheric and tonsillar retraction, cerebellomedullary fissure completely opening, and the uvulotonsillar and medullotonsillar space dissection sequentially, sometimes followed by the tela choroidea and inferior medullary velum opening depending on surgical require [186]. The telovelotonsillar segment of PICA is mostly relevant to the approach thus it is mostly likely to be injured, followed by tonsillomedullary segment [187]. Mechanical injury of them may cause PICA spasm, leading to ischemia and edema of dentate nucleus, which is associated with postoperative cerebellar mutism from several days to several months [188]. Rarely, during the retraction of tonsil the branches of PICA supplying pneumotaxic center of medulla can be damaged, causing temporary or permanent respiratory arrest $[1,186]$. In addition, the occlusion of PICA due to the surgery of fourth ventricle may cause corresponding manifestation such as LMS [182]. Therefore, it's of vital importance to protect the PICA carefully during operations, and utilizing endoscope can provide excellent visualization of PICA in order to reduce injury if necessary $[186,189]$. Besides telovelar approaches, the posterior fossa decompression treatment of Chiari I malformation, a congenital aplasia that cerebellar tonsils extends below the foramen magnum and into the upper spinal canal with or without symptom, makes the PICA under risk. Thus, delayed aneurysm probably forms during intradural exploration [190]. Furthermore, Nassr et al reported a rare case who had PICA distribution stroke due to injury of a variant PICA. The PICA was oppressed by $\mathrm{C} 1$ lateral mass screw after an occiput-C6 posterior spinal instrumentation with bilateral $\mathrm{C} 1$ lateral mass screw placement. Radiographic examinations showed that the left PICA arose between the C1 and C2 transverse 
foramena as mentioned above and went exactly posterior to the C1 lateral mass screw [191]. Won et al reported a similar case of extracranial origin of PICA [97]. Lateral mass screw fixation of the atlas was widely used in upper cervical spine surgery; these reports recommended that surgeon concern about the PICA anatomic variations to reduce complications.

Bypass surgeries often include PICA for revascularization, which were mainly applied in the treatment of those intractable PICA aneurysms such as giant aneurysm, aneurysm involving VA or the origin of PICA [192], hinting the surgical importance of PICA. Rarely, PICA-PICA in situ bypass can also be used in the treatment of BHS [174]. The bypass options can be divided into intracranial-intracranial (IC-IC) bypass and extracranial-intracranial (EC-IC) bypass [79, 193]. The former incudes in situ bypass with PICA-PICA bypass, reimplantation of the PICA to the proximal fourth segment of the VA and PICA reanastomosis after aneurysm excision [193]. The later mainly refers to occipital artery (OA)-PICA bypass. The caudal loop of PICA is recognized as the optimal receiving point of the bypass. However, as for those cases whose caudal loop are absent or in high position, accounting for about $28 \%$ [194], it is difficult to conduct the bypass directly thus alternative anastomosis sites should be explored through far-lateral approach [195]. Kim et al demonstrated successful OA-high-riding PICA bypass in 2 cases with anatomical variations of caudal loop [196]. Using radial artery interposition graft to realize the bypass of third segment of the VA and PICA might treat distal PICA aneurysms when other options were unsuitable [197].

In conclusion, PICA is easily injured during surgeries because of its special position, tortuous course and anatomical diversity. Surgeons need focus on the variations before the surgery and operate prudently, take advantage of endoscope when necessary to preserve PICA as possible. The anatomic features and course of PICA also play important roles in bypass surgeries, which emphasize the surgical importance of the vessel in the treatment of complex aneurysm and other rare diseases.

\section{Summary}

As the largest branch of VA, the PICA supplies critical regions of the medulla, fourth ventricle and cerebellum. The PICA can be involved in many diseases, including ischemic stroke, aneurysm, NVCS, AVM, and brain tumor etc. During surgeries associated with the telovelar approach, the PICA medulla segments should be preserved to prevent the infarction of the critical territory supplied by PICA. PICA frequently forms complex loops on the side of the brainstem, which distort the medulla and the cranial nerves and result in various NVCSs, MVD is a highly effective first-line choice for treatment. In ischemic strokes, rapid treatment is necessary to avoid obstructive hydrocephalus. Posterior fossa AVMs associated diseases including aneurysm and dissection involving PICA should be focused because of their high risk of rupture, worse outcome and treatment options. PICA can be injured by head trauma, which causes fatal SAH and should be early diagnosed and treated. VA terminating in PICA probably causes BHS. PICA supplies many brain tumors and can be used in intracerebellar chemotherapy. Thus, the PICA is the vessel of vital importance in practice.

Table 1 listed the outline and key important points of the clinical importance of PICA.

Table 1: Outline and key important points of the clinical importance of PICA

\begin{tabular}{ll}
\hline Outline & Key points \\
\hline Anatomy & The PICA is the largest branch of VA that supplies critical regions of \\
the medulla, fourth ventricle and cerebellum. It can be divided into 5 \\
segments containing anterior medullary, lateral medullary, \\
tonsillomedullary, telovelotonsillar, and cortical segment. It has close \\
relationship to lower CN.
\end{tabular}

\section{Abbreviations}

PICA: posterior inferior cerebellar artery; NVCS: neurovascular compression syndrome; AVM: arteriovenous malformation; LMS: lateral medullary 
syndrome; BHS: Bow hunter's syndrome; VA: vertebral artery; CN IX: glossopharyngeal nerve; $\mathrm{CN}$ $\mathrm{X}$ : vagus nerve; $\mathrm{CN}$ XI: accessory nerve; $\mathrm{CN}$ XII: hypoglossal nerve; $\mathrm{CN}$ VII: facial nerve; $\mathrm{CN}$ V: trigeminal nerve; BA: basilar artery; SCA: superior cerebellar artery; AICA: anterior inferior cerebellar artery; PPHA: primitive hypoglossal artery; PTA: primitive trigeminal artery; $\mathrm{SAH}$ : subarachnoid hemorrhage; IVH: intraventricular hemorrhage; MRA: magnetic resonance angiography; DSA: digital subtraction angiography; CTA: computed tomography angiography; EVT: endovascular treatment; mPICA: medial branch of the posterior inferior cerebellar artery; IPICA: lateral branch of the posterior inferior cerebellar artery; CT: computer tomography; MRI: magnetic resonance imaging; T2WI: T2-weighted images; FLAIR: fluid-attenuated inversion recovery; DWI: diffusion-weighted magnetic resonance imaging; HINTS: horizontal head impulse test, nystagmus and test of skew; rt-PA: recombinant tissue-type plasminogen activator; GPN: glossopharyngeal neuralgia; HeLPS: hemi-laryngopharyngeal spasm; HFS: hemifacial spasm; TN: trigeminal neuralgia; MCS: medullary compression syndrome; MVD: Microvascular decompression; IC-IC: intracranial-intracranial; EC-IC: extracranialintracranial; OA: occipital artery.

\section{Acknowledgements}

This work was supported by the National Key Research and Development Project (2016YFC13 01703), the Beijing Scientific and Technologic Project (D161100003816002) and Xuanwu Hospital HospitalLevel Foundation (XWJL-2019001).

\section{Competing Interests}

The authors have declared that no competing interest exists.

\section{References}

1. J. LR, Rhoton AL, Toshiom M, Peace DA. Microsurgical Anatomy of the Posterior Inferior Cerebellar Artery. Neurosurgery. 1982; 10(2):170-99.

2. Akar ZC, Dujovny M, Slavin KV, Gomez-Tortosa E, Ausman JI. Microsurgical anatomy of the intracranial part of the vertebral artery. Neurological Research. 1994; 16(3):171-80.

3. Patel Z, Abdulrahman AA. Morphometric study for the intracranial portion of the vertebral artery in human cadavers. Translational Research in Anatomy. 2020; 20.doi: 10.1016/j.tria.2020.100076.

4. Magklara EP, Pantelia ET, Solia E, Panagouli E, Piagkou M, Mazarakis A, et al. Vertebral artery variations revised: origin, course, branches and embryonic development. Folia Morphol (Warsz).2020 Feb 19. [Epub ahead of print].

5. Dzierzanowski J, Szarmach A, Bascik B, Czapiewski P, Muc A, Piskunowicz $M$, et al. Intracranial region of the vertebral artery: morphometric study in the context of clinical usefulness. Folia Morphol (Warsz). 2017; 76(3):379-87.

6. Rodriguez-Hernandez A, Rhoton AL, Jr., Lawton MT. Segmental anatomy of cerebellar arteries: a proposed nomenclature. Laboratory investigation. J Neurosurg. 2011; 115(2):387-97.

7. Tatu L, Moulin T, Bogousslavsky J, Duvernoy H. Arterial territories of human brain: brainstem and cerebellum. Neurology. 1996; 47(5):1125-35.
8. Sharifi M, Ciołkowski M, Krajewski P, Ciszek B. The choroid plexus of the fourth ventricle and its arteries. Folia morphologica. 2005; 64(3):194-8.

9. Icardo JM, Ojeda JL, Garcia-Porrero JA, Hurle JM. The cerebellar arteries: cortical patterns and vascularization of the cerebellar nuclei. Acta Anat (Basel). 1982; 113(2):108-16.

10. Fujii K, Lenkey C, Rhoton AL, Jr. Microsurgical anatomy of the choroidal arteries. Fourth ventricle and cerebellopontine angles. J Neurosurg. 1980; 52(4):504-24.

11. Bebin J. The cerebellopontile angle, the blood supply of the brain stem and the reticular formation. Anatomical and functional correlations relevant to surgery of acoustic tumors. Henry Ford Hosp Med J. 1968; 16(1):61-86.

12. Hagenah R, Kosak M, Freckmann N. Anatomic topographical relationship of the intraspinal accessory root to the upper cervical roots and to the vessels of the cranial cervical region. Acta Anat (Basel). 1983; 115(2):158-67.

13. Scialfa G, Bank W, Megret M, Corbaz JM, Salamon G. The arteries of the roof of the fourth ventricle. Neuroradiology. 1976; 11(2):69-71.

14. Wollschlaeger G, Wollschlaeger PB, Lucas FV, Lopez VF. Experience and result with postmortem cerebral angiography performed as routine procedure of the autopsy. Am J Roentgenol Radium Ther Nucl Med. 1967; 101(1):68-87.

15. Sharifi M, Ungier E, Ciszek B. Double posterior inferior cerebellar artery. Surg Radiol Anat. 2010; 32(1):87-9.

16. Lesley WS, Rajab MH, Case RS. Double Origin of the Posterior Inferior Cerebellar Artery: Association with Intracranial Aneurysm on Catheter Angiography. Ajr Am J Roentgenol. 2007; 189(4):893-7.

17. Silva MA, See AP, Aziz-Sultan MA, Patel NJ. Surgical Treatment of a Double Origin Posterior Inferior Cerebellar Artery Aneurysm and Insights From Embryology: Case Report and Literature Review. Oper Neurosurg (Hagerstown). 2017; 13(3):E8-e12.

18. Pekcevik Y, Pekcevik R. Variations of the cerebellar arteries at CT angiography. Surg Radiol Anat. 2014; 36(5):455-61.

19. Isaji T, Yasuda M, Kawaguchi R, Aoyama M, Niwa A, Nakura T, et al. Posterior inferior cerebellar artery with an extradural origin from the V3 segment: higher incidence on the nondominant vertebral artery. J Neurosurg Spine. 2018; 28(2):154-9.

20. Cavdar S, Dalcik H, Yalin A. A rare case of the posterior inferior cerebellar artery. Acta Anat (Basel). 1995; 152(3):234-6.

21. Liu IW, Ho BL, Chen CF, Han K, Lin CJ, Sheng WY, et al. Vertebral artery terminating in posterior inferior cerebellar artery: A normal variation with clinical significance. PLoS One. 2017;12(4):e0175264.

22. O'Donnell CM, Child ZA, Nguyen Q, Anderson PA, Lee MJ. Vertebral artery anomalies at the craniovertebral junction in the US population. Spine (Phila Pa 1976). 2014; 39(18):E1053-7.

23. Uchino A, Saito N, Watadani T, Okada Y, Kozawa E, Nishi N, et al. Vertebral artery variations at the C1-2 level diagnosed by magnetic resonance angiography. Neuroradiology. 2012; 54(1):19-23.

24. Ivashchuk G, Fries FN, Loukas M, Paulson D, Monteith SJ, Chapman JR, et al. Arterial variations around the atlas: a comprehensive review for avoiding neurosurgical complications. Childs Nerv Syst. 2016; 32(6):1093-100.

25. Wakao N, Takeuchi M, Nishimura M, Riew KD, Kamiya M, Hirasawa A, et al. Vertebral artery variations and osseous anomaly at the C1-2 level diagnosed by 3D CT angiography in normal subjects. Neuroradiology. 2014; 56(10):843-9.

26. K. BM, Ernesto C, Andrew J, Morcos JJ. Aneurysm of the Anterior Inferior Cerebellar Artery-Posterior Inferior Cerebellar Artery Variant: Case Report with Anatomical Description in the Cadaver. Neurosurgery. 2006; 2:2.

27. Ahuja A, Graves VB, Crosby DL, Strother CM. Anomalous origin of the posterior inferior cerebellar artery from the internal carotid artery. AJNR Am J Neuroradiol. 1992; 13(6):1625-6.

28. Kobayashi M, Akaji K, Tanizaki Y, Mihara B, Ohira T, Kawase T. Posterior inferior cerebellar artery aneurysm associated with persistent primitive hypoglossal artery. Neurol Med Chir (Tokyo). 2008; 48(6):259-61.

29. Lee SH, Koh JS, Lee CY. Trigeminal neuralgia caused by an anomalous posterior inferior cerebellar artery from the primitive trigeminal artery: case report. Cerebellum. 2011; 10(2):199-203.

30. Ogawa $\mathrm{T}$, Fujita $\mathrm{H}$, Inugami A, Shishido $\mathrm{F}$, Higano $\mathrm{S}$, Uemura $\mathrm{K}$. Anomalous origin of the posterior inferior cerebellar artery from the posterior meningeal artery. AJNR Am J Neuroradiol. 1991; 12(1):186.

31. Brzegowy K, Pękala PA, Zarzecki MP, Pękala JR, Roy J, Aziz HM, et al. Prevalence and Clinical Implications of the Primitive Trigeminal Artery and its Variants: A Meta-Analysis. World neurosurgery. 2020; 133(e): 401-411. 
32. Starnoni D, Maduri R, Al Taha K, Bervini D, Zumofen DW, Stienen MN, et al. Ruptured PICA aneurysms: presentation and treatment outcomes compared to other posterior circulation aneurysms. A Swiss SOS study. Acta Neurochir (Wien). 2019; 161(7):1325-34.

33. Xu F, Hong Y, Zheng Y, Xu Q, Leng B. Endovascular treatment of posterior inferior cerebellar artery aneurysms: a 7-year single-center experience. J Neurointerv Surg. 2017; 9(1):45-51.

34. Bohnstedt BN, Ziemba-Davis M, Edwards G, Brom J, Payner TD, Leipzig TJ, et al. Treatment and outcomes among 102 posterior inferior cerebellar artery aneurysms: a comparison of endovascular and microsurgical clip ligation. World Neurosurg. 2015; 83(5):784-93.

35. Petr O, Sejkorova A, Bradac O, Brinjikji W, Lanzino G. Safety and efficacy of treatment strategies for posterior inferior cerebellar artery aneurysms: a systematic review and meta-analysis. Acta Neurochir (Wien). 2016; 158(12):2415-28

36. Horiuchi T, Tanaka Y, Hongo K, Nitta J, Kusano Y, Kobayashi S. Characteristics of distal posteroinferior cerebellar artery aneurysms. Neurosurgery. 2003; 53(3):589-95; discussion 95-6.

37. Williamson RW, Wilson DA, Abla AA, McDougall CG, Nakaji P, Albuquerque FC, et al. Clinical characteristics and long-term outcomes in patients with ruptured posterior inferior cerebellar artery aneurysms: a comparative analysis. J Neurosurg. 2015; 123(2):441-5.

38. Foster MT, Herwadkar A, Patel HC. Posterior Inferior Cerebellar Artery/Vertebral Artery Subarachnoid Hemorrhage: A Comparison of Saccular vs Dissecting Aneurysms. Neurosurgery. 2018; 82(1):93-8.

39. Lim SM, Choi IS, Hum BA, David CA. Dissecting aneurysms of the distal segment of the posterior inferior cerebellar arteries: clinical presentation and management. AJNR Am J Neuroradiol. 2010; 31(6):1118-22.

40. Tawk RG, Bendok BR, Qureshi AI, Getch CC, Srinivasan J, Alberts M, et al. Isolated dissections and dissecting aneurysms of the posterior inferior cerebellar artery: topic and literature review. Neurosurg Rev. 2003; 26(3):180-7.

41. Varvari I, Bos EM, Dinkelaar W, van Es AC, Can A, Hunfeld M, et al. Fatal Subarachnoid Hemorrhage from an Aneurysm of a Persistent Primitive Hypoglossal Artery: Case Series and Literature Overview. World Neurosurg. 2018; 117:285-91.

42. Maeda K, Motoie R, Karashima S, Otsuji R, Ren N, Nagaoka S, et al. A case with coil embolization for ruptured aneurysm associated with fenestration of the posterior inferior cerebellar artery. Interv Neuroradiol. 2017; 23(6):632-5.

43. Akhtar S, Azeem A, Jiwani A, Javed G. Aneurysm in the anterior inferior cerebellar artery-posterior inferior cerebellar artery variant: Case report and review of literature. Int J Surg Case Rep. 2016; 22:23-7.

44. Savardekar A, Tewari MK, Garg R, Gupta V, Ahuja C. Extracranially located PICA aneurysm presenting with supratentorial IVH: A rare event with diagnostic pitfalls. J Neurosci Rural Pract. 2013; 4(Suppl 1):99-101.

45. Omoto K, Motoyama Y, Shida Y, Nakagawa I, Park YS, Nakase H. Effectiveness of Intraoperative Indocyanine Green Videoangiography in Avoiding Failure in Proximal Clipping for Dissecting Vertebral Artery Aneurysm Associated with Double Origin of the Posterior Inferior Cerebellar Artery. World Neurosurg. 2016; 90(708.e): 1-4.

46. Woo PY, Ko NM, Chan KY. Thrombosed large distal posterior inferior cerebellar artery aneurysm mimicking an infratentorial ependymoma. Case Rep Neurol Med. 2014; 2014:435953.

47. Lan ZG, Ma L, Duan J, You C. A fully thrombosed giant posterior inferior cerebellar aneurysm mimicking an intracranial tumour in a child. Br J Neurosurg. 2012; 26(6):888-90.

48. Li J, Lan Z, He M, You C. Multiple peripheral aneurysms of the posterior inferior cerebellar artery: Case report and review of the literature. Neurol India. 2009; 57(5):669-71.

49. Chou SN, Ortiz-Suarez HJ. Surgical treatment of arterial aneurysms of the vertebrobasilar circulation. J Neurosurg. 1974; 41(6):671-80.

50. Laine E. Arterial vertebro-basilar aneurysms. Prog Brain Res. 1968; 30:323-46.

51. Sharr MM, Kelvin FM. Vertebrobasilar aneurysms. Experience with 27 cases. Eur Neurol. 1973; 10(3):129-43.

52. Song J, Park JE, Chung J, Lim YC, Shin YS. Treatment strategies of ruptured posterior inferior cerebellar artery aneurysm according to its segment. Surg Neurol Int. 2017; 8:155.

53. Malik MT, Kenton Iii EJ, Vanino D, Dalal SS, Zand R. Lateral Medullary Ischemic Infarct Caused by Posterior Inferior Cerebellar Artery Aneurysm. Case Rep Neurol. 2017; 9(3):316-9.

54. Ekuma ME, Goto T, Hanaoka Y, Kanaya K, Horiuchi T, Hongo K, et al. Unilateral isolated hypoglossal nerve palsy due to pathologically adherent PICA fusiform aneurysm - A case report. Surg Neurol Int. 2017; 8:114.

55. Mou K, Zhou Z, Yin J, Yang H, Liu J. Clinical Features and Treatment of Distal Intracranial Aneurysms. J Craniofac Surg. 2016; 27 (3 e): 244-7.
56. Kanou Y, Arita K, Kurisu K, Ikawa F, Eguchi K, Monden S, et al. Dissecting aneurysm of the peripheral posterior inferior cerebellar artery. Acta Neurochir (Wien). 2000; 142(10):1151-6.

57. Komiya H, Saeki N, Iwadate Y, Sunami K, Yamaura A. [Posterior inferior cerebellar artery dissecting aneurysm presenting with Wallenberg's syndrome. Case report]. Neurol Med Chir (Tokyo). 1988; 28(4):404-8.

58. Parr M, Carminucci A, Al-Mufti F, Roychowdhury S, Gupta G. Isolated Abducens Nerve Palsy Associated with Ruptured Posterior Inferior Cerebellar Artery Aneurysm: Rare Neurologic Finding. World Neurosurg. 2019; 121:97-9.

59. Burkhardt JK, Winkler EA, Lasker GF, Yue JK, Lawton MT. Isolated abducens nerve palsy associated with subarachnoid hemorrhage: a localizing sign of ruptured posterior inferior cerebellar artery aneurysms. J Neurosurg. 2018; 128(6):1830-8.

60. Zhang Y, Sun S, Xu Q, Feng W, Chen H. Posterior Inferior Cerebellar Artery Aneurysm: Have You Ever Been Misdiagnosed? Acad Radiol. 2018; 25(12):1564-7.

61. Narducci A, Xu R, Vajkoczy P. Decision Making in Surgery for Nonsaccular Posterior Inferior Cerebellar Artery Aneurysms With Special Reference to Intraoperative Assessment of Collateral Blood Flow and Neurophysiological Function. Oper Neurosurg (Hagerstown). 2018; 14(4):422-31.

62. Tokimura H, Yamahata H, Kamezawa T, Tajitsu K, Nagayama T, Sugata $\mathrm{S}$, et al. Clinical presentation and treatment of distal posterior inferior cerebellar artery aneurysms. Neurosurg Rev. 2011; 34(1):57-67.

63. Schievink WI, Wijdicks EF, Piepgras DG, Chu CP, O'Fallon WM, Whisnant JP. The poor prognosis of ruptured intracranial aneurysms of the posterior circulation. J Neurosurg. 1995; 82(5):791-5.

64. Thompson BG, Brown RD, Jr., Amin-Hanjani S, Broderick JP, Cockroft KM, Connolly ES, Jr., et al. Guidelines for the Management of Patients With Unruptured Intracranial Aneurysms: A Guideline for Healthcare Professionals From the American Heart Association/American Stroke Association. Stroke. 2015; 46(8):2368-400.

65. Chen X, Sun Z, Shi L, Xu L, Yu J, Fang B, et al. Endovascular management of ruptured distal posterior inferior cerebellar artery aneurysms: A retrospective cohort study. Medicine (Baltimore). 2018; 97(49 e): 13300 .

66. Li H, Li XF, He XY, Zhang X, Zhu GH, Fang QR, et al. Endovascular Treatment of Dissecting Aneurysms of the Posterior Inferior Cerebellar Artery and Predictors of Outcome. J Stroke Cerebrovasc Dis. 2015; 24(9):2134-42.

67. Oguz S, Dinc H. Treatment of posterior inferior cerebellar artery aneurysms using flow-diverter stents: A single-center experience. Interv Neuroradiol. 2019; 25(4):407-13.

68. Atallah E, Saad H, Li J, Kumar A, Tjoumakaris S, Chalouhi N, et al. The Experience With Flow Diverters in the Treatment of Posterior Inferior Cerebellar Artery Aneurysms. Oper Neurosurg (Hagerstown). 2019; 17(1):8-13.

69. Aronov M, Mokin M, Zelenkov A, Popugaev K, Tsarikaev A, Reutov A. Endovascular Coiling of Ruptured Very Small Dissecting Fusiform Aneurysm of Posterior Inferior Cerebellar Artery with Parent Artery Preservation by Microcatheter Auto-Assistance. World Neurosurg. 2019; 121:152-5.

70. Mittal S, Singh V, Phadke RV, Neyaz Z. Endovascular treatment of ruptured pica aneurysms and association with its extradural origin: A single-center experience. Indian J Radiol Imaging. 2018; 28(2):232-8.

71. Madaelil TP, Wallace AN, Chatterjee AN, Zipfel GJ, Dacey RG, Jr., Cross DT, 3rd, et al. Endovascular parent vessel sacrifice in ruptured dissecting vertebral and posterior inferior cerebellar artery aneurysms: clinical outcomes and review of the literature. J Neurointerv Surg. 2016; 8(8):796-801.

72. Juszkat R, Kram P, Stanislawska K, Jankowski R, Stachowska-Tomczak B, Nowak S, et al. Ten years of experience in endovascular treatment of ruptured aneurysms of the posterior inferior cerebellar artery. Interv Neuroradiol. 2016; 22(2):129-37.

73. Brassel F, Melber K, Schlunz-Hendann M, Meila D. Kissing-Y stenting for endovascular treatment of complex wide necked bifurcation aneurysms using Acandis Acclino stents: results and literature review. J Neurointerv Surg. 2016; 8(4):386-95.

74. Rennert RC, Strickland BA, Ravina K, Bakhsheshian J, Fredrickson V, Tenser M, et al. Efficacy and Outcomes of Posterior Inferior Cerebellar Artery (PICA) Bypass for Proximal PICA and Vertebral Artery-PICA Aneurysms: A Case Series. Oper Neurosurg (Hagerstown). 2018; 15(4):395-403.

75. Palanisamy D, Yasuhiro Y, Kyosuke M, Tsukasa K, Katsumi T, Kato Y. Transcondylar Fossa Approach to Unruptured Vertebral Artery and Vertebral Artery-Posterior Inferior Cerebellar Artery Aneurysms: Surgical Outcome. World Neurosurg. 2018; 119:e783-e91. 
76. Nussbaum ES, Kallmes KM, Lassig JP, Goddard JK, Madison MT, Nussbaum LA. Cerebral revascularization for the management of complex intracranial aneurysms: a single-center experience. J Neurosurg. 2018; p:1-11.

77. Seoane P, Kalb S, Clark JC, Rivas JC, Xu DS, Mendes GAC, et al. Far-Lateral Approach Without Drilling the Occipital Condyle for Vertebral Artery-Posterior Inferior Cerebellar Artery Aneurysms. Neurosurgery. 2017; 81(2):268-74.

78. Bonda DJ, Labib M, Katz JM, Ortiz RA, Chalif D, Setton A, et al. Intracranial Bypass of Posterior Inferior Cerebellar Artery Aneurysms: Indications, Technical Aspects, and Clinical Outcomes. Oper Neurosurg (Hagerstown). 2017; 13(5):586-95.

79. Abla AA, McDougall CM, Breshears JD, Lawton MT. Intracranial-to-intracranial bypass for posterior inferior cerebellar artery aneurysms: options, technical challenges, and results in 35 patients. J Neurosurg. 2016; 124(5):1275-86.

80. Lee SH, Choi SK. In Situ Intersegmental Anastomosis within a Single Artery for Treatment of an Aneurysm at the Posterior Inferior Cerebellar Artery: Closing Omega Bypass. J Korean Neurosurg Soc. 2015; 58(5):467-70.

81. Cho KC, Kim YB, Suh SH, Joo JY, Hong CK. Multidisciplinary management for the treatment of proximal posterior inferior cerebellar artery aneurysms. Neurol Res. 2017; 39(5):403-13.

82. Di Somma A, Cancela Caro P, Blanco MO, Somma T, Lopez-Gonzalez A, Campero A, et al. Modified "Extended" Suboccipital Subtonsillar Clipping of a Ruptured Proximal Pica Aneurysm: Technical Note with Relevant Anatomical Demonstration. World Neurosurg. 2018; 117:301-8.

83. La Pira B, Sturiale CL, Della Pepa GM, Albanese A. Surgical approach to posterior inferior cerebellar artery aneurysms. Acta Neurochir (Wien). 2018; 160(2):295-9.

84. Mascitelli JR, Yaeger K, Wei D, Kellner CP, Mocco J. Multimodality Treatment of Posterior Inferior Cerebellar Artery Aneurysms. World Neurosurgery. 2017; 106.

85. Abouka?S R, Zairi F, Boustia F, Bourgeois P, Leclerc X, Lejeune JP. Vertebral artery-posterior inferior cerebellar artery convergence aneurysms treated by endovascular or surgical treatment: Mid- and long-term outcome. Neurochirurgie. 2016; 62(2):72-7.

86. Venti M. Cerebellar Infarcts and Hemorrhages. Front Neurol Neurosci. 2012; 30:171-5.

87. Lee H. Neuro-otological aspects of cerebellar stroke syndrome. J Clin Neurol. 2009;5(2):65-73.

88. Lee H, Sohn SI, Cho YW, Lee SR, Ahn BH, Park BR, et al. Cerebellar infarction presenting isolated vertigo: Frequency and vascular topographical patterns. Neurology. 2006; 67(7):1178-83.

89. Barth A, Bogousslavsky J, Regli F. Infarcts in the territory of the lateral branch of the posterior inferior cerebellar artery. J Neurol Neurosurg Psychiatry. 1994; 57(9):1073-6.

90. SYDNEY S. THE ARTERIAL RELATIONS OF THE INTERNAL AUDITORY MEATUS. Brain. 1945; 68:23-7.

91. Lee H. Sudden deafness related to posterior circulation infarction in the territory of the nonanterior inferior cerebellar artery: frequency, origin, and vascular topographical pattern. Eur Neurol. 2008; 59(6):302-6.

92. Kumral E, Kisabay A, Atac C, Calli C, Yunten N. Spectrum of the posterior inferior cerebellar artery territory infarcts. Clinical-diffusion-weighted imaging correlates. Cerebrovasc Dis. 2005; 20(5):370-80

93. Lee SH, Cha JH, Jung IE, Yu SW, Moon JS, Cho KH, et al. Relationship between the Angle of the Posterior Inferior Cerebellar Artery and Cardioembolic Stroke. J Stroke Cerebrovasc Dis. 2019; 28(3):693-8.

94. Matsumoto J, Ogata T, Abe H, Higashi T, Inoue T. Do Characteristics of Dissection Differ Between the Posterior Inferior Cerebellar Artery and the Vertebral Artery? Journal of Stroke \& Cerebrovascular Diseases. 2014; 23(10):2857-61.

95. Kobayashi J, Ohara T, Shiozawa M, Minematsu K, Nagatsuka K, Toyoda K. Isolated Posterior Inferior Cerebellar Artery Dissection as a Cause of Ischemic Stroke: Clinical Features and Prognosis. Cerebrovascular Diseases. 2015; 40(5-6):215-21.

96. Jeong DK, Hwang SK. A Case of Posterior Inferior Cerebellar Artery Infarction after Cervical Chiropractic Manipulation. Korean J Neurotrauma. 2018; 14(2):159-63.

97. Won D, Lee JM, Park IS, Lee CH, Lee K, Kim JY, et al. Posterior Inferior Cerebellar Artery Infarction Originating at C1-2 after C1-2 Fusion. Korean J Neurotrauma. 2019; 15(2):192-8.

98. Edlow JA, Newman-Toker DE, Savitz SI. Diagnosis and initial management of cerebellar infarction. Lancet Neurol. 2008;7(10):951-64.

99. Moreau F, Patel S, Lauzon ML, McCreary CR, Goyal M, Frayne R, et al. Cavitation after acute symptomatic lacunar stroke depends on time, location, and MRI sequence. Stroke. 2012; 43(7):1837-42.
100. De Cocker LJ, Geerlings MI, Hartkamp NS, Grool AM, Mali WP, Van der Graaf Y, et al. Cerebellar infarct patterns: The SMART-Medea study. Neuroimage Clin. 2015;8:314-21.

101. Oppenheim C, Stanescu R, Dormont D, Crozier S, Marro B, Samson Y, et al. False-negative diffusion-weighted MR findings in acute ischemic stroke. AJNR Am J Neuroradiol. 2000;21(8):1434-40.

102. Chen L, Lee W, Chambers BR, Dewey HM. Diagnostic accuracy of acute vestibular syndrome at the bedside in a stroke unit. Journal of Neurology. 2011;258(5):p.855-61.

103. Tarnutzer AA, Berkowitz AL, Robinson KA, Hsieh YH, Newman-Toker DE. Does my dizzy patient have a stroke? A systematic review of bedside diagnosis in acute vestibular syndrome. CMAJ: Canadian Medical Association journal. 2011; 183(9E):571-592.

104. Powers WJ, Rabinstein AA, Ackerson T, Adeoye OM, Bambakidis NC, Becker K, et al. Guidelines for the Early Management of Patients With Acute Ischemic Stroke: 2019 Update to the 2018 Guidelines for the Early Management of Acute Ischemic Stroke: A Guideline for Healthcare Professionals From the American Heart Association/American Stroke Association. Stroke. 2019;50(12 e): 344-418.

105. Ozdemir G. Selective intra-arterial recombinant tissue-plasminogen activator in a case of acute posterior inferior cerebellar artery occlusion. Acta Neurol Belg. 2020;120(4):935-937.

106. Hankey GJ. Secondary stroke prevention. Lancet Neurol. 2014; 13(2):178-94.

107. Koh MG, Phan TG, Atkinson JLD, Wijdicks EFM. Neuroimaging in Deteriorating Patients With Cerebellar Infarcts and Mass Effect. Stroke. 2000; 31(9):2062-7.

108. Neugebauer H, Witsch J, Zweckberger K, Jüttler E. Space-occupying cerebellar infarction: Complications, treatment, and outcome. Neurosurgical Focus. 2013; 34(5):E8.

109. Wijdicks EF, Sheth KN, Carter BS, Greer DM, Kasner SE, Kimberly WT, et al. Recommendations for the management of cerebral and cerebellar infarction with swelling: a statement for healthcare professionals from he American Heart Association/American Stroke Association. Stroke. 2014; 45(4):1222-38

110. Tartara F, Bongetta D, Colombo EV, Bortolotti C, Cenzato M, Giombelli E, et al. Strokectomy and Extensive Cerebrospinal Fluid Drainage for the Treatment of Space-Occupying Cerebellar Ischemic Stroke. World Neurosurg. 2018; 115(e): 80-84.

111. Saleem F, J MD. Lateral Medullary Syndrome. StatPearls. Treasure Island (FL): StatPearls PublishingStatPearls Publishing LLC. 2020.

112. Lui F, Tadi P, Anilkumar AC. Wallenberg Syndrome. StatPearls. Treasure Island (FL): StatPearls Publishing StatPearls Publishing LLC. 2020

113. Merwick A, Werring D. Posterior circulation ischaemic stroke. Bmj. 2014; 348(g):3175.

114. Kim JS. Pure lateral medullary infarction: clinical-radiological correlation of 130 acute, consecutive patients. Brain. 2003; 126(Pt 8):1864-72.

115. Park MG, Choi JH, Yang TI, Oh SJ, Baik SK, Park KP. Spontaneous isolated posterior inferior cerebellar artery dissection: rare but underdiagnosed cause of ischemic stroke. J Stroke Cerebrovasc Dis. 2014; 23(7):1865-70

116. Razak A, Clark D, Farooq MU, Kassab MY. Wallenberg's syndrome with extradural-extracranial origin of the posterior inferior cerebellar artery. Neurol Sci. 2011; 32(4):711-3

117. Kim H, Lee HJ, Park JW. Clinical course and outcome in patients with severe dysphagia after lateral medullary syndrome. Ther Adv Neurol Disord. 2018; 11:1756286418759864.

118. Wilkins RH. Neurovascular Compression Syndromes. Neurologic Clinics. 1985; 3(2):359-72.

119. Haller S, Etienne L, Ko?vari E, Varoquaux AD, Urbach H, Becker M. Imaging of Neurovascular Compression Syndromes: Trigeminal Neuralgia, Hemifacial Spasm, Vestibular Paroxysmia, and Glossopharyngeal Neuralgia. Ajnr American Journal of Neuroradiology. 2016; 37(8):1384.

120. Xia L, Li YS, Liu MX, Zhong J, Dou NN, Li B, et al. Microvascular decompression for glossopharyngeal neuralgia: a retrospective analysis of 228 cases. Acta Neurochir (Wien). 2018; 160(1):117-23.

121. Manzoni GC, Torelli P. Epidemiology of typical and atypical craniofacial neuralgias. Neurol Sci. 2005;26 Suppl 2:s65-7.

122. Chen J, Sindou M. Vago-glossopharyngeal neuralgia: a literature review of neurosurgical experience. Acta Neurochir (Wien). 2015; 157(2):311-21; discussion 21.

123. Barbash GI, Keren G, Korczyn AD, Sharpless NS, Chayen M, Copperman Y, et al. Mechanisms of syncope in glossopharyngeal neuralgia. Electroencephalogr Clin Neurophysiol. 1986; 63(3):231-5. 
124. Esaki T, Osada H, Nakao Y, Yamamoto T, Maeda M, Miyazaki T, et al. Surgical management for glossopharyngeal neuralgia associated with cardiac syncope: two case reports. Br J Neurosurg. 2007;21(6):599-602.

125. Honey CR, Gooderham P, Morrison M, Ivanishvili Z. Episodic hemilaryngopharyngeal spasm (HELPS) syndrome: case report of a surgically treatable novel neuropathy. J Neurosurg. 2017;126(5):1653-6.

126. Honey CR, Morrison MD, Heran MKS, Dhaliwal BS. Hemi-laryngopharyngeal spasm as a novel cause of inducible laryngeal obstruction with a surgical cure: report of 3 cases. J Neurosurg. 2018; p:1-5.

127. Honey CM, Kruger MT, Rheaume AR, Avecillas-Chasin JM, Morrison MD, Honey CR. Concurrent Glossopharyngeal Neuralgia and Hemi-Laryngopharyngeal Spasm (HeLPS): A Case Report and a Review of the Literature. Neurosurgery. 2019; 12(nyz):546. [Epub ahead of print].

128. Chopade TR, Bollu PC. Hemifacial Spasm. StatPearls. Treasure Island (FL): StatPearls Publishing StatPearls Publishing LLC.; 2020.

129. Hermier M. Imaging of hemifacial spasm. Neurochirurgie. 2018;64(2):117-23

130. Mercier P, Sindou M. The conflicting vessels in hemifacial spasm: Literature review and anatomical-surgical implications. Neurochirurgie. 2018;64(2):94-100

131. Rhoton AL, Jr. The cerebellopontine angle and posterior fossa cranial nerves by the retrosigmoid approach. Neurosurgery. 2000;47(3 Suppl):S93-129.

132. Chung M, Han I, Chung SS, Huh R. Side predilections of offending arteries in hemifacial spasm. J Clin Neurosci. 2016;29:106-10.

133. Cruccu G, Di Stefano G, Truini A. Trigeminal Neuralgia. The New England journal of medicine. 2020; 383(8):754-62.

134. Lee SH, Koh JS, Lee CY. Trigeminal neuralgia caused by an anomalous posterior inferior cerebellar artery from the primitive trigeminal artery: case report. Cerebellum (London, England). 2011; 10(2):199-203.

135. Hui MS, Choi WM, Liu HM, Huang KM, Perng HL, Chen LK. Anomalous origin of the posterior inferior cerebellar artery from the pre-cavernous portion of the internal carotid artery--a primitive trigeminal artery variant. European journal of radiology. 1994;19(1):10-3.

136. Jannetta PJ, Gendell HM. Clinical observations on etiology of essential hypertension. Surg Forum. 1979; 30:431-2.

137. Jannetta PJ, Segal R, Wolfson SK, Jr. Neurogenic hypertension: etiology and surgical treatment. I. Observations in 53 patients. Ann Surg. 1985; 201(3):391-8.

138. Naraghi R, Gaab MR, Walter GF, Kleineberg B. Arterial hypertension and neurovascular compression at the ventrolateral medulla. A comparative microanatomical and pathological study. J Neurosurg. 1992; 77(1):103-12.

139. Ciriello J, Caverson MM, Polosa C. Function of the ventrolateral medulla in the control of the circulation. Brain Res. 1986; 396(4):359-91.

140. Doba N, Reis DJ. Acute fulminating neurogenic hypertension produced by brainstem lesions in the rat. Circ Res. 1973; 32(5):584-93.

141. Granata AR, Ruggiero DA, Park DH, Joh TH, Reis DJ. Lesions of epinephrine neurons in the rostral ventrolateral medulla abolish the vasodepressor components of baroreflex and cardiopulmonary reflex. Hypertension. 1983; 5(6 Pt 3):V80-4

142. Kutty RK, Yamada Y, Takizawa K, Kato Y. Medullary Compression Due to Ectatic Vertebral Artery-Case Report and Review of Literature. J Stroke Cerebrovasc Dis. 2020; 29(1):104460.

143. Simpson BA, Amato-Watkins A, Hourihan MD. Hemibody pain relieved by microvascular decompression of the contralateral caudal medulla: case report. Pain. 2014; 155(8):1667-72.

144. Lutz J, Thon N, Stahl R, Lummel N, Tonn JC, Linn J, et al. Microstructural alterations in trigeminal neuralgia determined by diffusion tensor imaging are independent of symptom duration, severity, and type of neurovascular conflict. J Neurosurg. 2016;124(3):823-30.

145. Holste KG, Hardaway FA, Raslan AM, Burchiel KJ. Pain-free and pain-controlled survival after sectioning the nervus intermedius in nervus intermedius neuralgia: a single-institution review. J Neurosurg. 2018; 131(2):352-9.

146. Best C, Gawehn J, Kramer HH, Thomke F, Ibis T, Muller-Forell W, et al. MRI and neurophysiology in vestibular paroxysmia: contradiction and correlation. J Neurol Neurosurg Psychiatry. 2013; 84(12):1349-56.

147. Liu J, Shen Y, Jiang B, Yuan Y, Yu Y. Ameliorating Effect of Microvascular Decompression on Patients with Coexistence of Hemifacial Spasm and Glossopharyngeal Neuralgia: A Retrospective Study. World Neurosurg. 2020; 133:e62-e7.

148. Kobata H, Kondo A, Iwasaki K, Nishioka T. Combined hyperactive dysfunction syndrome of the cranial nerves: trigeminal neuralgia, hemifacial spasm, and glossopharyngeal neuralgia: 11-year experience and review. Neurosurgery. 1998; 43(6):1351-61; discussion 61-2.
149. Baldauf J, Rosenstengel C, Schroeder HWS. Nerve Compression Syndromes in the Posterior Cranial Fossa. Dtsch Arztebl Int. 2019; 116(4):54-60.

150. Li Y, Mao F, Cheng F, Peng C, Guo D, Wang B. A Meta-Analysis of Endoscopic Microvascular Decompression versus Microscopic Microvascular Decompression for the Treatment for Cranial Nerve Syndrome Caused by Vascular Compression. World Neurosurg. 2019; 126:647-55.e7.

151. Zhao H, Tang Y, Zhang X, Zhu J, Yuan Y, Zhou P, et al. Long-term Outcomes of Microvascular Decompression in the Treatment of Hemifacial Spasm Based on Different Offending Vessels. J Neurol Surg A Cent Eur Neurosurg. 2019; 80(4):285-90.

152. Gabriel RA, Kim H, Sidney S, McCulloch CE, Singh V, Johnston SC, et al. Ten-year detection rate of brain arteriovenous malformations in a large, multiethnic, defined population. Stroke. 2010; 41(1):21-6.

153. Rispoli R, Di Chirico A, Sibille M, Carletti S. A juvenile case of cerebellar arteriovenous malformation with gradual onset of dysphoria and headache. Neuroradiol J. 2013; 26(3):333-7.

154. Kaptain GJ, Lanzino G, Do HM, Kassell NF. Posterior inferior cerebellar artery aneurysms associated with posterior fossa arteriovenous malformation: report of five cases and literature review. Surg Neurol. 1999; 51(2):146-52.

155. Akeret K, Germans M, Sun W, Kulcsar Z, Regli L. Subarachnoid Hemorrhage Due to Flow-Related Dissection of the Posterior-Inferior Cerebellar Artery Associated with a Distal Arteriovenous Malformation. World Neurosurg. 2019; 125:44-8.

156. Stein KP, Wanke I, Forsting M, Oezkan N, Huetter BO, Sandalcioglu IE, et al. Associated Aneurysms in Infratentorial Arteriovenous Malformations: Role of Aneurysm Size and Comparison with Supratentorial Lesions. Cerebrovasc Dis. 2016; 41(5-6):219-25.

157. Hung AL, Yang W, Braileanu M, Garzon-Muvdi T, Caplan JM, Colby GP, et al. Risk Assessment of Hemorrhage of Posterior Inferior Cerebellar Artery Aneurysms in Posterior Fossa Arteriovenous Malformations. Oper Neurosurg (Hagerstown). 2018; 14(4):359-66.

158. Kouznetsov E, Weill A, Ghostine JS, Gentric JC, Raymond J, Roy D. Association between posterior fossa arteriovenous malformations and prenidal aneurysm rupture: potential impact on management. Neurosurg Focus. 2014; 37(3):E4.

159. Azzam CJ. Growth of multiple peripheral high flow aneurysms of the posterior inferior cerebellar artery associated with a cerebellar arteriovenous malformation. Neurosurgery. 1987; 21(6):934-9.

160. Case D, Kumpe D, Cava L, Neumann R, White A, Roark C, et al. Ruptured Distal Posterior Inferior Cerebellar Artery (PICA) Aneurysms Associated with Cerebellar Arterial Venous Malformations (AVMs): A Case Series and Review of the Literature Demonstrating the Need for Angiographic Evaluation and Feasibility of Endovascular Treatment. World Neurosurg. 2017; 97:(751e)7-13.

161. Hodozuka A, Sako K, Yonemasu Y, Suzuki N, Fujita T, Ohgami S. [Spontaneous disappearance of aneurysm after total removal of accompanying intracranial arteriovenous malformation. Case report]. Neurol Med Chir (Tokyo). 1991; 31(13):966-71.

162. Kominami S, Watanabe A, Kobayashi S, Teramoto A. Ruptured feeder aneurysm associated with cerebellar arteriovenous malformation. J Nippon Med Sch. 2012; 79(4):296-300.

163. Purgina B, Milroy CM. Fatal traumatic aneurysm of the posterior inferior cerebellar artery with delayed rupture. Forensic Sci Int. 2015; 247(e): 1-5.

164. Binning MJ, Hauschild TB, Amini A, MacDonald JD. Delayed post-traumatic saccular aneurysm of PICA in an adolescent. Acta Neurochir (Wien). 2009; 151(12):1647-8.

165. Lee SH, Moon JU, Choi SK, Choi MK, Lee J, Sung JY. Pseudoaneurysm at the Distal Posterior Inferior Cerebellar Artery After Blunt Head Trauma: A Case Report and Review of the Literature. World Neurosurg. 2016; 92:580.e11-.e15.

166. Nishioka T, Maeda Y, Tomogane Y, Nakano A, Arita N. Unexpected delayed rupture of the vertebral-posterior inferior cerebellar artery aneurysms following closed head injury. Acta Neurochir (Wien). 2002; 144(8):839-45; discussion 45.

167. Sure U, Becker R, Petermeyer M, Bertalanffy H. Aneurysm of the posterior inferior cerebellar artery caused by a traumatic perforating artery tear-out mechanism in a child. Childs Nerv Syst. 1999; 15(6-7):354-6.

168. Liu JK, Decker D, Tenner MS, Couldwell WT, Chiles BW, 3rd. Traumatic arteriovenous fistula of the posterior inferior cerebellar artery treated with endovascular coil embolization: case report. Surg Neurol. 2004; 61(3):255-60; discussion 61

169. Kibayashi K, Ng'walali PM, Hamada K, Honjyo K, Hamada K, Tsunenari S. Traumatic basal subarachnoid hemorrhage due to rupture of the posterior inferior cerebellar artery--case report. Neurol Med Chir (Tokyo). 2000; 40(3):156-9. 
170. Bostrom K, Helander CG, Lindgren SO. Blunt basal head trauma: rupture of posterior inferior cerebellar artery. Forensic Sci Int. 1992; 53(1):61-8.

171. Mao Z, Wang N, Hussain M, Li M, Zhang H, Zhang Q, et al. Traumatic intracranial aneurysms due to blunt brain injury-a single center experience. Acta Neurochir (Wien). 2012; 154(12):2187-93; discussion 93.

172. Burton C, Velasco F, Dorman J. Traumatic aneurysm of a peripheral cerebral artery. Review and case report. J Neurosurg. 1968; 28(5):468-74.

173. Jost GF, Dailey AT. Bow hunter's syndrome revisited: 2 new cases and literature review of 124 cases. Neurosurg Focus. 2015; 38(4):E7.

174. Duan G, Xu J, Shi J, Cao Y. Advances in the Pathogenesis, Diagnosis and Treatment of Bow Hunter's Syndrome: A Comprehensive Review of the Literature. Interv Neurol. 2016; 5(1-2):29-38

175. Schunemann V, Kim J, Dornbos D, 3rd, Nimjee SM. C2-C3 Anterior Cervical Arthrodesis in the Treatment of Bow Hunter's Syndrome: Case Report and Review of the Literature. World Neurosurg. 2018; 118:284-9.

176. Kan P, Yashar P, Langer DJ, Siddiqui AH, Levy EI. Posterior inferior cerebellar artery to posterior inferior cerebellar artery in situ bypass for the treatment of Bow hunter's-type dynamic ischemia in holovertebral dissection. World Neurosurg. 2012; 78(5e): 15-7.

177. Patel NP, Robinson TM, Lesley WS, Garrett D, Shan Y, Huang JH. Retromedullary Hemangioblastoma Mimicking a Posterior Inferior Cerebellar Artery Aneurysm: Case Report and Literature Review. World Neurosurg. 2019; 122:165-70.

178. Yan Y, Wang H, Xu T, Gong Z, Hong F, Zhang X, et al. Resection of a Meningioma at Craniocervical Junction through Far Lateral Approach: Two-Dimensional Operative Video. J Neurol Surg B Skull Base. 2019; 80(Suppl 4):358-9.

179. Sayyahmelli S, Ucer M, Baskaya MK. Microsurgical Gross Total Resection of a WHO Grade II Cerebellopontine Angle Ependymoma in an Adult. J Neurol Surg B Skull Base. 2018; 79(Suppl 5):426-7.

180. Pojskic M, Nguyen VN, Boop FA, Arnautovic KI. Microsurgical Resection of the IV Ventricle Subependymoma: 2-Dimensional Operative Video. Oper Neurosurg (Hagerstown). 2020;19(1 E): 66-67.

181. Chen Q, Ren J, Xu J, Yang X, Guo Z. Concurrent Bronchial Artery and Posterior Inferior Cerebellar Artery Microcatheter Interventional Chemotherapy for Adenocarcinoma of the Lung with Solitary Cerebellar Metastasis. Med Sci Monit. 2019; 25:6504-11.

182. Matsushima T, Rhoton AL, Jr., Lenkey C. Microsurgery of the fourth ventricle: Part 1. Microsurgical anatomy. Neurosurgery. 1982; 11(5):631-67.

183. Ziyal IM, Sekhar LN, Salas E. Subtonsillar-transcerebellomedullary approach to lesions involving the fourth ventricle, the cerebellomedullary fissure and the lateral brainstem. Br J Neurosurg. 1999; 13(3):276-84.

184. Shigeno T, Kumai J, Endo M, Hotta S. [Surgery of AVM of the inferior medullary velum by the uvulotonsillar approach--advantage of moving of the cerebellar tonsil: technical case report]. No Shinkei Geka. 2002; 30(1):87-92.

185. Abe H, Miki K, Kobayashi H, Ogata T, Iwaasa M, Matsushima T, et al. Unilateral Trans-cerebellomedullary Fissure Approach for Occipital Artery to Posterior Inferior Cerebellar Artery Bypass during Aneurysmal Surgery. Neurol Med Chir (Tokyo). 2017; 57(6):284-91.

186. Ghali MGZ. Telovelar surgical approach. Neurosurg Rev. 2019 Dec 5. doi: 10.1007/s10143-019-01190-5. [Epub ahead of print].

187. Ucerler H, Saylam C, Cagli S, Orhan M, Zileli M. The posterior inferior cerebellar artery and its branches in relation to the cerebellomedullary fissure. Clin Anat. 2008; 21(2):119-26.

188. Ersahin Y, Mutluer S, Cagli S, Duman Y. Cerebellar mutism: report of seven cases and review of the literature. Neurosurgery. 1996; 38(1):60-5; discussion 6 .

189. Eissa EM. The Role of the Telovelar Approach in Fourth Ventricular Surgery: A New Perspective. Turk Neurosurg. 2018;28(4):523-9.

190. McClugage SG, Oakes WJ. The Chiari I malformation. J Neurosurg Pediatr. 2019; 24(3):217-26.

191. Nassr AN, Swann PP, Huston J, 3rd, Abdelfatah MM, Rose PS, Currier BL. Aberrant posterior inferior cerebellar artery injury with $\mathrm{C} 1$ lateral mass screw placement: a case report and review of the literature. Spine J. 2014; 14(9):e7-14.

192. Davies JM, Lawton MT. Advances in open microsurgery for cerebral aneurysms. Neurosurgery. 2014; 74 (Suppl 1):7-16.

193. Crowley RW, Medel R, Dumont AS. Operative nuances of an occipital artery to posterior inferior cerebellar artery bypass. Neurosurg Focus. 2009; 26(5 E): 19.

194. Macchi V, Porzionato A, Parenti A, De Caro R. The course of the posterior inferior cerebellar artery may be related to its level of origin. Surg Radiol Anat. 2004; 26(1):60-5.

195. Fukuda H, Evins AI, Iwasaki K, Hattori I, Murao K, Kurosaki Y, et al. The role of alternative anastomosis sites in occipital artery-posterior inferior cerebellar artery bypass in the absence of the caudal loop using the far-lateral approach. J Neurosurg. 2017; 126(2):634-44.

196. Kim YJ, Kim JY, Cho YH, Kim YS, Kim TS, Joo SP. Preoperative Considerations in Occipital Artery-high-riding Posterior Inferior Cerebellar Artery Bypass: A Report of Two Cases and a Literature Review. J Neurol Surg A Cent Eur Neurosurg. 2019; 80(5):399-403.

197. Czabanka M, Ali M, Schmiedek P, Vajkoczy P, Lawton MT. Vertebral artery-posterior inferior cerebellar artery bypass using a radial artery graft for hemorrhagic dissecting vertebral artery aneurysms: surgical technique and report of 2 cases. J Neurosurg. 2011; 114(4):1074-9. 